\title{
Eating Disorder Tendencies and "Subjective" Loss Of Control Experience in People Dieting With Normal Body Mass Index* Sultan Okumusoglu ${ }^{1}$ \\ ${ }^{1}$ (Psychology Department, European University of Lefke, North Cyprus, ssehitoglu@eul.edu.tr)
}

\begin{abstract}
The aim of the present study is investigation of eating disorder tendency and "subjective" loss of control experience in terms of adherence to diet in women who are dieting with normal BMI. According to results of the present study no statistically significant BMI differences was found between dieters and undieters and dieting women differed significantly from undieting group with higher eating disorder tendency scores which is parallel with the suggestions which implies that dieting with normal BMI might be accepted as a risk factor regarding eating disorders. According to REZZY cut points the group above the cut point differed with higher mean scores on diet related dysfunctional attitudes scores than the group below the cut point. Regression analysis revealed that the best predictor of the eating disorder tendencies is "subjective experience" of loss of control regarding eating, in other words "subjective perception" of unsuccessful diet adherence. Besides having practical and theoretical relevance results also points out the possible risks of food restriction and dieting. Future studies are needed and also proposed to clarify related factors which might be effective in terms of development or maintenance of eating disorders
\end{abstract}

Keywords - Eating disorders, weight loss, dieting, BMI

\section{INTRODUCTION}

Eating disorders like Anorexia Nervosa (AN), Bulimia Nervosa (BN), Binge Eating Disorder (BED) are related with having a pathological relationship in terms of food, eating, body weight and shape and related compensatory behaviors (American Psychological Association [APA], 2013). According to Cognitive Theories of eating disorders cognitive schemas are fundamental in terms of relevant cognitive biases and distortions. Individual's cognitive schemas form the basis of cognitive distortions related with body shape and eating behavior. According to the model these cognitive distortions are percept as "absolute truths" by sufferers of eating disorders (Williamson, Muller, Reas, \& Thaw, 1999; Williamson, White, York-Crowe, \& Stewart, 2004). On the other hand increasing prevalence (APA, 2013) and mortality rates of eating disorders (Arcelus, Mitchell, Wales, \& Nielsen, 2011; Steinhausen, 2002) are other factors which are increasing the extent of the problem. The interval for normal Body Mass Index (BMI) is determined as $18,5 \mathrm{~kg} / \mathrm{m}^{2}$ to $24,9 \mathrm{~kg} / \mathrm{m}^{2}$ (WHO, 2016). People who are dieting with normal BMI are accepted under the risk of developing food, eating, shape or weight related problems as obesity or overweight. Also they are under the risk of developing an eating related disorder (Wardle et al., 2002). It is worth to consider that people with eating disorders or obesity are both having a diet history which implies diet history could be one of the important risk factors in terms of relevant pathologies. According to literature, relevant cognitions and cognitive distortions must be studied to be able to handle an increasing success in terms of assessment and treatment of eating disorders (O'Connor \& Dowrick, 1987; Shafran \& Robinson, 2004). Investigating eating attitudes and relevant cognitions is important not just for assessment but also in terms of prevention and treatment. Increasing relevant information is beneficial for application but it is also beneficial regarding theory of eating disorders. Therefore the aim of the present study is investigation of eating disorder tendencies and "subjective" loss of control experience regarding adherence to diet in women who are dieting with normal BMI.

\section{Participants}

\section{METHOD}

Participants are 88 women with normal body mass index (BMI) which ranges between 18, 5 and 24,9 $\mathrm{kg} / \mathrm{m}^{2}$. BMI was calculated through division of the weight of the individual $(\mathrm{kg})$ with height squared $(\mathrm{m})$ (WHO, 2016). The age range of the participants is $18-24(\mathrm{M}=20,03, \mathrm{SD}=1,53)$. The mentioned age range was chosen since it is informed as the range which has the highest increase in terms of Anorexia Nervosa eating disorder (Hoek \& Hoeksen, 2003). 44 of these 88 women have been applied to get professional diet help for weight reduction from a nutrition and dietetic professional. Undieting group; the other 44 women who are not

*This study have been presented at "5-6 May VIIIth Işık Savaşır Symposium" and an abstract of the oral presentation took place at the proceedings.

dieting are at the same age range with the dieting group. All participants are volunteered to answer the scales. 
Scales

Demographics scale, eating disorder tendencies scale (REZZY/SCOFF) and Diet related Dysfunctional Attitudes Scale which was developed to measure saboteur believes regarding diet in people with obesity have been used.

\section{Demographics Scale}

Participants' age, gender, weight, height and BMI have been handled through this scale.

\section{REZZY (SCOFF) Eating Disorder Tendencies Scale}

The scale which measures eating disorder tendencies has five items. Original scale (SCOFF Eating Disorder Tendencies Scale) was developed by Morgan, Reid and Lacey (2000). After Turkish version of the scale was validated it was named as REZZY (Aydemir, Köksal, YalınSapmaz \& Yüceyar, 2015). Cronbach's alpha score of the scale is .74. If the total scale score which calculated by summing the responses for each item is $2 \geq$ it is accepted as an score that is above the pathological cut point of the scale.

\section{Diet Related Dysfunctional Attitudes Scale}

This scale was developed to measure saboteur, dysfunctional diet related attitudes in people with obesity (Okumuşoğlu, 2015). Cronbach's alpha score of the scale is .88 and correlation between two halves was .59 (Okumuşoğlu, 2015). Scale has 18 items. Since it is measuring diet related dysfunctional thoughts it is thought that scale will be beneficial to handle "subjective" loss of control experience regarding adherence to following diet.

\section{RESULTS}

Analysis of Variance (ANOVA) Between Dieting and Undieting Groups

According to statistical analysis of data dieting group differs significantly from undieting group in terms of REZZY scores $\left(F(1,86)=50.834, \mathrm{p}<.05, \eta^{2}=.37\right)$. Dieters $(\mathrm{M}=1.88, \mathrm{SD}=.86)$ differed significantly from undieters $(\mathrm{M}=.77, \mathrm{SD}=.56)$ with higher mean scores.

Dieters $(M=67.09, S D=13.02)$ and undieters $(M=46.06, S D=11.01)$ with normal BMI also differed significantly in terms of diet related dysfunctional attitudes scale scores with higher mean scores $\left(\mathrm{F}(1,86)=66.87, \mathrm{P}<.05, \eta^{2}=.43\right)$.

Any statistically significant difference could not be detected in terms of BMI between dieters and undieters.

\section{Analysis of Variance (ANOVA) Between Groups According to REZZY Cut Point $(\geq \mathbf{2})$}

One way ANOVA between groups which determined according to REZZY cut points was found significant $\left(F(1,86)=28.17, \mathrm{p}<.05, \eta^{2}=.24\right)$. The group with scores $2 \geq(\mathrm{n}=34)(\mathrm{M}=66.52, \mathrm{SD}=11.45)$ and the group with scores $2<(\mathrm{n}=54) \quad(\mathrm{M}=50.31, \mathrm{SD}=15.30)$ differed significantly in terms of diet related saboteur cognitions which reveals "subjective" loss of control over adherence to diet.

Statistically significant ANOVA results can be seen in Table 1. and descriptive statistics of ANOVA can be seen in Table 2 .

Table 1. ANOVA Results Between Groups

\begin{tabular}{|lcccc|}
\hline Variables & Grup & $\mathbf{F}$ & $\mathbf{p}<.05$ & $\eta^{2}$ \\
\hline REZZY & Diet Condition & $50.834^{*}$ & .000 & .37 \\
\hline DRDAS & Diet Condition & $66.871^{*}$ & .000 & .43 \\
\hline DRDAS & REZZY Cutpoint & $28.177 *$ & .000 & .24 \\
\hline
\end{tabular}

* $\mathrm{p}<.05$ Diet Condition:Dieting $(\mathrm{n}=44)$ and Undieting $(\mathrm{n}=44)$ Groups. REZZY Cut Point:REZZY $\geq 2(\mathrm{n}=34) \&$

REZZY<2 ( $\mathrm{n}=54)$. DRDAS: Diet Related Dysfunctional Attitudes Scale

Table 2. Descriptive Statistics of ANOVA

\begin{tabular}{|llccc|}
\hline Variables & Group & M & SD & N(88) \\
\hline REZZY & Dieting & 1.88 & .86 & 44 \\
& Undieting & .77 & .56 & 44 \\
\hline \multirow{2}{*}{ DRDAS } & Dieting & 7.09 & 13.02 & 44 \\
& Undieting & 46.06 & 11.01 & 44 \\
\hline \multirow{2}{*}{ DRDAS } & REZZY $\geq 2$ & 66.52 & 11.45 & 34 \\
& REZZY<2 & 50.31 & 15.30 & 54 \\
\hline
\end{tabular}

\section{Regression Analysis}

Stepwise regression analyses have been conducted. According to results diet related dysfunctional attitudes was predicting .23 of the variance of REZZY scores. BMI and age did not enter the equation. As can be seen from the results as REZZY scores increase diet related dysfunctional attitudes are also increase $(r=0.475)$. (See Table 3.) 
Eating Disorder Tendencies And "Subjective" Loss Of Control Experience In

Table 3. Significant Predictors of Eating Disorder Tendencies According to Stepwise Regression Analysis

\begin{tabular}{|llllllll|}
\hline Predictors & $\mathrm{R}$ & $\mathrm{R}^{2}$ & $\mathrm{~B}$ & Beta & Std.Error & $\mathrm{F}$ & $\mathrm{p}$ \\
\hline DRDAS & .475 & .226 & .027 & .475 & .005 & 25.089 & .00 \\
& & & & & & & \\
\hline
\end{tabular}

\section{DISCUSSION}

As can be seen from the results of statistical analysis, dieting and undieting groups are differed significantly in terms of REZZY scores which reveal eating disorder tendencies. Dieting women differed significantly from undieting women with higher eating disorder tendency scores and this finding is parallel with the suggestion which points out that dieting and food restriction have possible negative influences regarding food-weight relationship (Wardle et al., 2002) One way ANOVA between groups which determined according to REZZY cut points was found significant. The group above the cut point differed with higher mean scores on diet related dysfunctional attitudes scores than the group below the cut point. It means the group with eating disorder tendencies differed significantly in terms of diet related saboteur cognitions which reveals "subjective" loss of control over adherence to diet. In this study dieter group differed significantly with higher mean scores from undieter group in terms of diet related dysfunctional attitudes scores. According to cognitive model of eating disorders cognitive distortions are percept as "absolute truths" by people with eating disorders (Williamson, Muller, Reas, \& Thaw, 1999; Williamson, White, York-Crowe, \& Stewart, 2004). Since dieters scores regarding "subjective experience" of unsuccessful diet adherence is higher than scores of undieters it can be said that this finding of the present study is providing support to the model's claim. As can be seen from the findings diet related dysfunctional attitudes scale scores are predicting the .23 of the variance of REZZY scores. In other words the best predictor of the eating disorder tendencies are "subjective experience" of loss of control and hence "subjective perception" of unsuccessful diet adherence. This finding is also parallel with the previously mentioned results and claims of cognitive model of eating disorders. Food restriction is informed as having negative effect in terms of individual's relationship with food (Wardle et all. 2002). It was also suggested that people with diet history have higher risk regarding development of future overweight and obesity problems (Wardle et all. 2002). These mentioned suggestions are parallel with the results of the present study.

On the other hand no statistically significant BMI differences were found between dieters and undieters. Finding suggests that dieting and undieting groups have no significant weight differences inside the mentioned normal BMI range which was $18,55-24,99 \mathrm{~kg} / \mathrm{m}^{2}$ (WHO, 2016) that leads one group to need to diet. Result implies that the dieting group's preference to diet is related with "subjective" reasons as psychological and cognitive reasons which is parallel with eating disorder tendencies and hence implies that dieting with normal BMI might be accepted as a risk factor regarding eating disorders. Unnecessary dieting efforts might be not just a symptom but also a triggering factor regarding eating disorders. Beside since dieting history is also related with future overweight and obesity problems (Wardle et all. 2002) perhaps it is time to assess the advantages and disadvantages of dieting. Future studies regarding these questions are proposed.

It was suggested that the "subjective experience" of loss of control over eating is an indicator of eating disorder psychopathology (Mond et al., 2006). Findings of the present study are also can be accepted as parallel with this claim. Relationship of eating disorder related cognitions and "subjective experience" of lack of diet adherence should be investigated with various samples. Beside probable maintaining factors should also be investigated by future studies. Lack of inclusion of possible maintaining factors and various samples can be mentioned as limitations of the present study.

Relevant cognitive distortions must be studied to be able to handle an increasing success in terms of assessment and treatment of eating disorders (Shafran \& Robinson, 2004) which shows an increasing prevalence. Therefore studies investigating eating attitudes and relevant cognitions are important not just for assessment but also in terms of risk assessment, in terms of prevention and treatment. Increase in relevant information will also be beneficial regarding theory of eating disorders. It is hoped that results of the present study will add to the cumulative knowledge in the eating disorders field. Beside practical benefits, findings of the present study can be thought as having theoretical relevance with the cognitive model of eating disorders.

\section{REFERENCES}

[1] American Psychiatric Association. (2013). Diagnostic and Statistical Manual of Mental Disorders (Fifth Ed.). Arlington, VA, American Psychiatric Publishing.

[2] Arcelus, J., Mitchell, A.J., Wales, J., \& Nielsen, S. (2011). Mortality rates in patients with anorexia nervosa and other eating disorders.:A Meta-analysis of 36 Studies. Archives of General Psychiatry,68(7),724-731 
[3] Aydemir, Ö. Köksal, B., Yalın Sapmaz, Ş., \& Yüceyar, H. (2015). Kadın üniversite öğrencilerinde REZZY Yeme Bozuklukları Ölçeği Türkçe formunun güvenilirlik ve geçerliliği. Anadolu Psikiyatri Dergisi, 16 (Özel sayı.1), 31-35.

[4] Morgan, J. F., Reid, F., \& Lacey, J. H. (2000). The SCOFF questionnaire: A new screening tool for eating disorders. Western Journal of Medicine, 172(3), 164-165.

[5] O’Connor, O. J., \& Dowrick, P. W. (1987). Cognitions in normal weight, overweight, and previously overweight adults. Cognitive Therapy and Research, 3 (11), 315-326.

[6] Okumuşoğlu, S. (2015). Reliability, validity and factor analysis of dysfunctional attitudes scale of obesity and automatic thoughts scale of obesity. International Journal of Management and Humanities (IJMH), 1 (6), 11-17.

[7] Shafran,R., \& Robinson,P. (2004). Thought shape fusion in eating disorders. British Journal of Clinical Psychology, 43, 399-407.

[8] Steinhausen, H. C. (2002).The outcome of anorexia nervosa in the 20th century. American Journal of Psychiatry, 159, 1284- 1293.

[9] Wardle, J., Griffith, J., Johnson, F., \& Rapoport, L. (2000). Intentional weight control and food choice habits in a national representative sample of adults in the UK. International Journal of Obesity Related Metabolic Disorders. 24, 534 - 540.

[10] Williamson,D.A., Muller, S.L., Reas, D.L., \& Thaw, J.M.(1999). Cognitive bias in eating disorders: Implications for theory and treatment. Behavior Modification, 23, 556-577.

[11] Williamson, D.A., White, M.A., York-Crowe, E., \& Stewart, T.M. (2004). Cognitive-Behavioral Theories of Eating Disorders, Behavior Modification, 28 (6), 711-738. 